University of Wollongong

Research Online

Faculty of Engineering and Information

Faculty of Engineering and Information

Sciences - Papers: Part A

Sciences

2014

\title{
High di-electric constant nano-structure ceramics synthesis using novel electric discharge assisted mechanical milling and magneto ball milling and its properties
}

Azrin A. Chowdhury

University of Wollongong, ac526@uowmail.edu.au

Andrzej Calka

University of Wollongong, acalka@uow.edu.au

David Wexler

University of Wollongong, davidw@uow.edu.au

Konstantin Konstantinov

University of Wollongong, konstan@uow.edu.au

Follow this and additional works at: https://ro.uow.edu.au/eispapers

Part of the Engineering Commons, and the Science and Technology Studies Commons

Research Online is the open access institutional repository for the University of Wollongong. For further information contact the UOW Library: research-pubs@uow.edu.au 


\title{
High di-electric constant nano-structure ceramics synthesis using novel electric discharge assisted mechanical milling and magneto ball milling and its properties
}

\begin{abstract}
The conventional method to prepare functional oxides is ceramicpowder- based processing typically via solid-state reaction of microcrystalline starting powders at high temperatures. Disadvantages of this approach include the high temperatures of reaction, limited degree of product chemical homogeneity and difficulties in achieving rapid sintering. Various chemicalbased processing routes have been developed to prepare powders of more homogeneous composition, improved reactivity and sintering ability at low temperatures. Regardless of the route chosen to synthesise complex oxides, almost all of them require lengthy heat treatment schedules that usually exceed $10 \mathrm{~h}$, as well as multi-stage processing steps. We describe two approaches to address these problems, applied to successful synthesis of both MgAl2O4 and $\mathrm{CaCu} 3 \mathrm{Ti} 4012$ (CCT) oxides exhibiting excellent di-electric properties. One approach employed the novel direct synthesis technique of electric discharge assisted mechanical milling (EDAMM) and the second used the more conventional method of controlled ball milling using the magneto-mechanical method followed by heat treatment of nano-structural products. By using EDAMM, nano-crystalline precursors for transformation into high di-electric constant ceramics could be formed in as little as $0.1 \%$ of the processing time required for conventional solid-state techniques while ball milling using the magneto method also resulted in nano-structural precursors powders suitable for reaction by heat treatment to form oxide supercapacitor. Sample characterisation was carried out using XRD, TEM and SEM. Di-electric property measurements were performed using AC-LCR and by DC meters. Copyright 2014 Inderscience Enterprises Ltd.
\end{abstract}

\section{Keywords}

electric, constant, nano, structure, ceramics, synthesis, novel, discharge, high, assisted, di, mechanical, milling, magneto, ball, its, properties

\section{Disciplines \\ Engineering | Science and Technology Studies}

\section{Publication Details}

Chowdhury, A. A., Calka, A., Wexler, D. \& Konstantinov, K. (2014). High di-electric constant nano-structure ceramics synthesis using novel electric discharge assisted mechanical milling and magneto ball milling and its properties. International Journal of Nanotechnology, 11 (9/10/11), 728-736. 


\title{
High di-electric constant nano-structure ceramics synthesis using novel electric discharge assisted mechanical milling and magneto ball milling and its properties
}

\author{
A.A. Chowdhury*, A. Calka, D. Wexler \\ and K. Konstantinov
}

School of Mechanical, Materials and Mechatronic Engineering, University of Wollongong,

NSW 2522, Australia

E-mail: ac526@uowmail.edu.au

E-mail: acalka@uow.edu.au

E-mail: david_wexler@uow.edu.au

E-mail: konstan@uow.edu.au

${ }^{*}$ Corresponding author

\begin{abstract}
The conventional method to prepare functional oxides is ceramicpowder-based processing typically via solid-state reaction of microcrystalline starting powders at high temperatures. Disadvantages of this approach include the high temperatures of reaction, limited degree of product chemical homogeneity and difficulties in achieving rapid sintering. Various chemicalbased processing routes have been developed to prepare powders of more homogeneous composition, improved reactivity and sintering ability at low temperatures. Regardless of the route chosen to synthesise complex oxides, almost all of them require lengthy heat treatment schedules that usually exceed $10 \mathrm{~h}$, as well as multi-stage processing steps. We describe two approaches to address these problems, applied to successful synthesis of both $\mathrm{MgAl}_{2} \mathrm{O}_{4}$ and $\mathrm{CaCu}_{3} \mathrm{Ti}_{4} \mathrm{O}_{12}(\mathrm{CCT})$ oxides exhibiting excellent di-electric properties. One approach employed the novel direct synthesis technique of electric discharge assisted mechanical milling (EDAMM) and the second used the more conventional method of controlled ball milling using the magneto-mechanical method followed by heat treatment of nano-structural products. By using EDAMM, nano-crystalline precursors for transformation into high di-electric constant ceramics could be formed in as little as $0.1 \%$ of the processing time required for conventional solid-state techniques while ball milling using the magneto method also resulted in nano-structural precursors powders suitable for reaction by heat treatment to form oxide supercapacitor. Sample characterisation was carried out using XRD, TEM and SEM. Di-electric property measurements were performed using AC-LCR and by DC meters.
\end{abstract}

Keywords: electric discharge assisted mechanical milling; high di-electric constant; nano-structure ceramic.

Reference to this paper should be made as follows: Chowdhury, A.A., Calka, A., Wexler, D. and Konstantinov, K. (2014) 'High di-electric constant nano-structure ceramics synthesis using novel electric discharge assisted mechanical milling and magneto ball milling and its properties', Int. J. Nanotechnol., Vol. 11, Nos. 9/10/11, pp.728-736. 
Biographical notes: Azrin Akhter Chowdhury is currently doing her $\mathrm{PhD}$ at Materials Engineering Department, University of Wollongong. She is former lecturer at Aeronautical College of Bangladesh. She received her Bachelor's Degree from Bangladesh University of Engineering Technology (BUET) in 2008. After that, she worked as a Research Assistant from 2009 to 2010 on nano-particles-incorporated epoxy polymer.

Andrzej Calka received his PhD from Warsaw University of Technology. From 1983 to 1995, he was a research fellow at Australian National University. Since 1995, he has been working at the Faculty of Engineering, University of Wollongong. His current research activities include materials synthesis and processing, mechanical alloying and mechano-chemistry for developing new materials, rapid solidification processing of metallic materials, metal casting, solidification and heat treatment, materials characterisation, etc. He is the author and co-author of more than 152 journal papers and one book.

David Wexler is a Senior Research Fellow at the University of Wollongong with expertise in Advanced Materials Synthesis, Materials Characterisation and Physical Metallurgy, and has contributed to over 140 authored or co-authored journal papers in these fields. He received his MSc from Melbourne University and $\mathrm{PhD}$ from Monash University specialising in advanced techniques of electron microscopy.

Konstantin Konstantinov is currently working as a Senior Lecturer in Australian Institute for Innovative Materials at the University of Wollongong. He has more than 25 years career as an internationally recognised expert on engineering of multifunctional ceramic nano-composites for various applications and as a developer of mass-production nano-technologies for ceramic synthesis. He is the initiator and coordinator of a new multidisciplinary research direction at UoW entitled 'Application of Advanced Nanoceramics for Health Protection'.

This paper is a revised and expanded version of a paper entitled 'Synthesis and properties of high dielectric constant ceramics using novel electric discharge assisted mechanical milling and magneto ball milling' presented at E-MRS, European Material Research Society, Strasbourge, France, 28 May 2013.

\section{Introduction}

The demand for energy storage and energy production is growing with our global population increases and rapid industrialisation. The combination of a technologically advanced modern society and predictions of a future global energy crisis demands the implementation and design of new low-cost, highly efficient and multifunctional frameworks for energy storage. As a result, energy storage systems such as batteries, fuel cells and supercapacitor technologies are being adapted and optimised, particularly using high surface area nano-structured components [1-5]. New materials with high di-electric constants and low loss tangents are needed in the electronics industry. The conventional method to prepare di-electric oxides is ceramic-powder-based processing, i.e., through solid-state reaction at high temperatures [6,7]. When the precursor powders are coarse grained, this process has approached several disadvantages, including the high temperatures required for reaction, long sintering times and the limited degree of 
chemical homogeneity of products. To address these drawbacks, several chemical-based processing routes, including freeze-drying [8,9], spray-pyrolysis [10,11], sol-gel [12,13], spray-drying [14] and pyrolysis of complex compounds [15,16], have been developed to prepare precursor powders of more homogeneous composition, improved reactivity and increased sinter ability at lower temperatures. In this paper, we present application of the extremely rapid synthesis method of electric discharge assisted mechanical milling (EDAMM) for the synthesis of high purity single phase multi-element supercapacitor oxides. The oxides synthesised were formed in as little as $0.1 \%$ of the processing time required using conventional solid-state techniques. We also present application of magneto-ball milling for the formation of very reactive nano-crystalline powders that could form final products during sintering at much lower temperatures than in the case of conventional solid-state synthesis from coarse-grained precursor powders. Using EDAMM, high purity single-phase multi-element oxides can be formed in as little as $0.1 \%$ of the processing time required in conventional solid-state techniques.

The main advantage of using magneto-ball milling is formation of very reactive nano-crystalline powders that could form final products during sintering at lower temperatures than in the case of conventional solid-state synthesis.

\section{Experimental}

Starting powders of $\mathrm{CaO} 9.14 \%, \mathrm{TiO}_{2} 52.16 \%$ and $\mathrm{CuO} 38.70 \%$ and $\mathrm{MgO} 28.27 \%$ and $\mathrm{Al}_{2} \mathrm{O}_{3} 71.725 \mathrm{wt} \%$ were combined in stoichiometric proportions to produce the compound oxides, $\mathrm{CaCu}_{3} \mathrm{Ti}_{4} \mathrm{O}_{12}$ (CCT) and $\mathrm{MgAl}_{2} \mathrm{O}_{4}$, respectively, and then mechanically pre-mixed in a conventional ball mill for $1 \mathrm{~h}$ under a high purity argon atmosphere.

Electric discharge assisted mechanical milling (EDAMM) was performed in a modified vibrational laboratory rod mill for periods of 10 mins. The mill was designed to produce a milling mode combining a repeated impact of a curved rod end on powder particles, placed on a vibrating hemispherical container under electrical conditions of pulsed discharges (Figure 1). During milling, pulsed discharges are initiated at the tip of the rod and travel through the milling atmosphere and powders before terminating in the base at the centre of the hemispherical milling cell. The power supply unit is custom built specifically for discharge milling. Radio frequency impulses are generated with voltages in the $\mathrm{kV}$ range and currents in the $\mathrm{mA}$ range. During vibration, the electric circuit is broken by small gaps between the stainless steel rod and the milling chamber base. This results in the generation of pulsed electric discharges, which travel across this gap and complete the electric circuit. All milling experiments were carried out in a high purity Ar atmosphere.

It has been known that reactive nano-structured materials can be formed by ball milling [17]. In this work, we also used a ball milling device (Uni-Ball-Mill) that provides control of milling parameters such as milling energy, ball movement pattern and shearing to impact ratio[18]. Schematic representation of this type of milling device is seen in Figure 2. This is a planetary ball mill that consists of a few hardened steel balls confined in a stainless steel cell. The ball movement during the milling process is confined to the vertical plane by cell walls and is controlled by an external magnetic field generated by FeNdB magnets. The intensity and direction of the field can be externally adjusted to allow the ball trajectories, impact energy and the shearing energy to be varied 
in a controlled manner. By selecting appropriate milling conditions, we are able to reduce the cold welding of soft metals, and enhance nano-crystalline particle evolution, thereby producing a large volume of the interfacial component of the nano-structure with crystal size reduced to less than $25 \mathrm{~nm}$.

Figure 1 Schematic representation of the electric discharge assisted mechanical milling (EDAMM) method (see online version for colours)

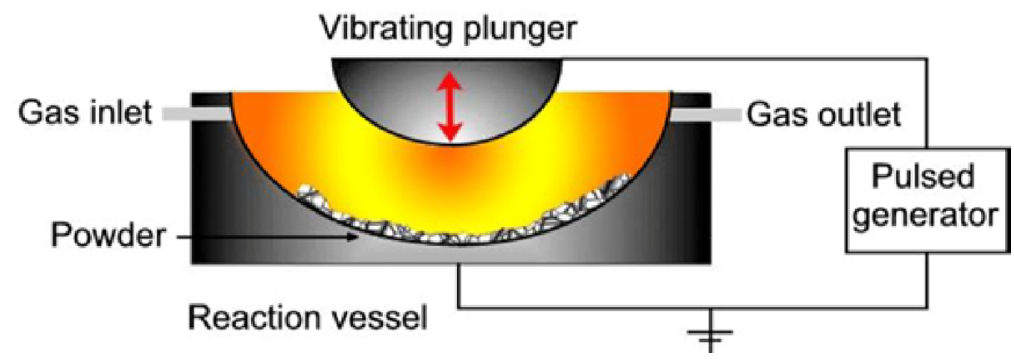

Figure 2 Schematic representation of the uniball mill device used in this work (see online version for colours)

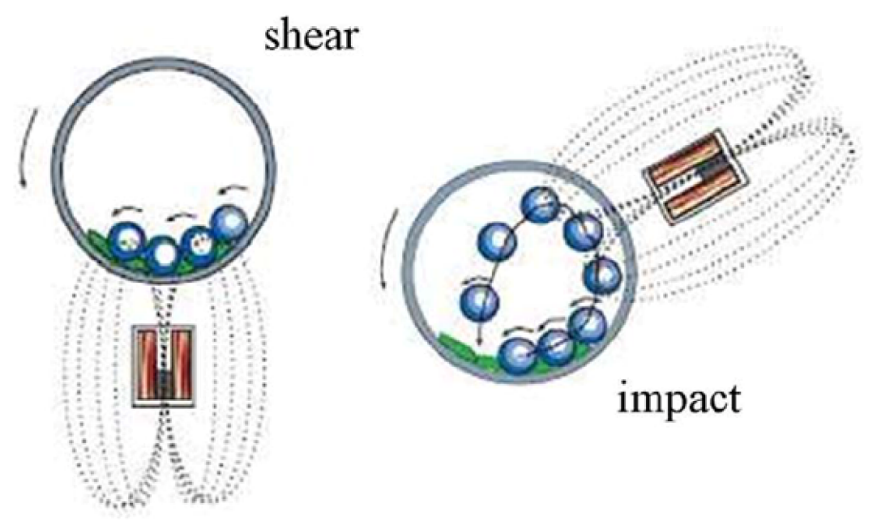

To identify the crystalline phase and structure, X-ray diffraction (XRD) patterns were recorded on a multipurpose $\mathrm{X}$-ray diffraction system with a $\mathrm{Cu} \mathrm{K \alpha}$ radiation source at $40 \mathrm{kV}$ and $30 \mathrm{~mA}$. The morphology was observed using a transmission electron microscope (TEM, JEOL 2011 instrument) and scanning electron microscope (SEM; JEOL JSM-70001F instrument) with energy-dispersive X-ray spectroscopy (EDS). Di-electric properties of powder compressed into pallets were measured at ambient temperature using a $\mathrm{TH} 2817 \mathrm{~B}$ impedance analyser within frequency range of $50 \mathrm{~Hz}-100 \mathrm{kHz}$.

\section{Results and discussion}

Figure 3 shows XRD results obtained after 120 hours uniball milling of the $\mathrm{CaO}, \mathrm{TiO}_{2}$, $\mathrm{CuO}$ mixture, with wide diffraction peaks consistent with formation of a nano-structural product. After sintering for 24 hours, sharp XRD peaks result, which can be indexed according to $\mathrm{CaCu}_{3} \mathrm{Ti}_{4} \mathrm{O}_{12}(\mathrm{CCT})$ phase (PDF021-0140). Figure 4 presents $\mathrm{MgO}+\mathrm{Al}_{2} \mathrm{O}_{3}$ 
premixed powders milled in magneto-ball milling for 120 hours under both gentle shearing mode, with magnets positioned at the bottom of the milling chamber, and under impact mode where magnets are positioned at the side of the mills and ball particle impact is significant. Milling under shear indicates less contamination than impact milling.

Figure $3 \mathrm{XRD}$ pattern obtained from the $\mathrm{CaO}, \mathrm{TiO}_{2}$ and $\mathrm{CuO}$ mixture milled for 120 hours under shearing mode (black) and then hot pressed (see online version for colours)

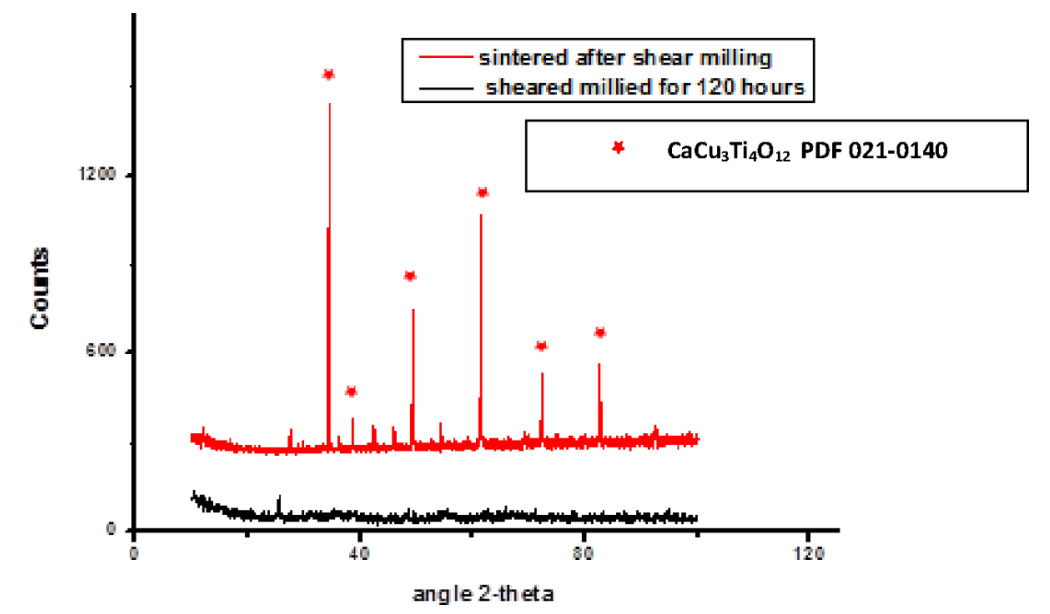

Figure 4 XRD peaks correspond to MgAl2O4 phase (PDF 01-1154), MgO (PDF 45-0946) (see online version for colours)

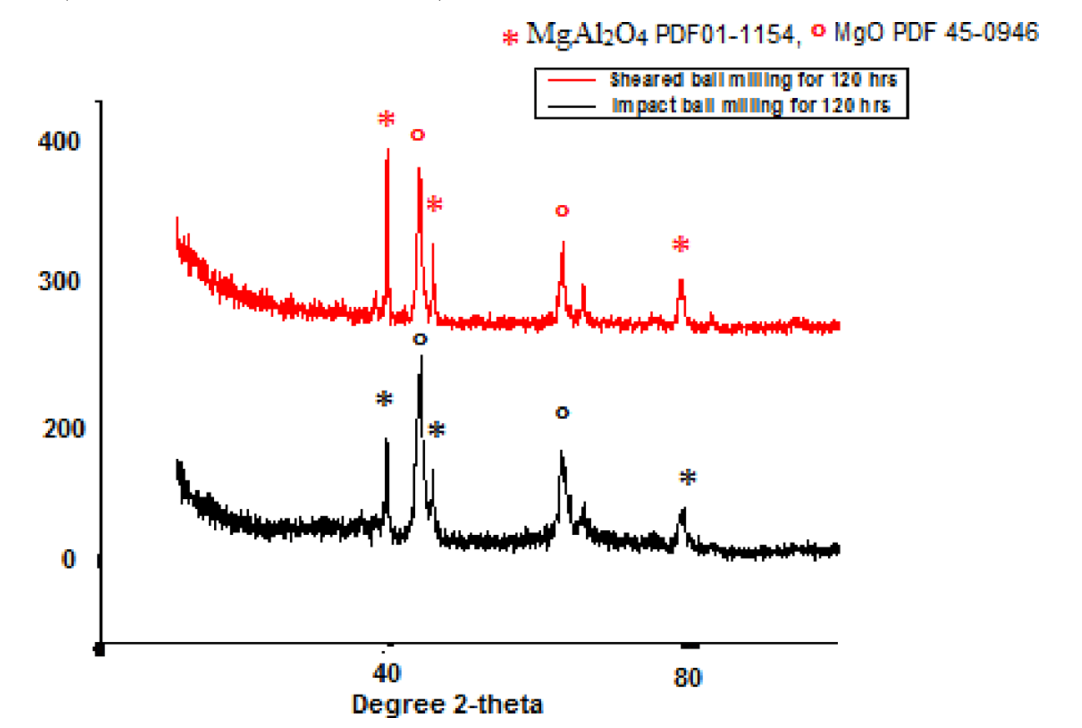

EDAMM processing: X-ray diffraction indicated the direct formation of nano-structured $\mathrm{MgAl}_{2} \mathrm{O}_{4}$ and $\mathrm{CCT}$ products after EDAMM processing of elemental oxide starting powders. Figures 5 and 6 show XRD results indicating $\mathrm{MgAl}_{2} \mathrm{O}_{4}$ and $\mathrm{CCT}$ product formation after 10 minutes of EDAMM processing of oxide mixtures. The ultrafine- 
grained products were confirmed by TEM imaging. Figure 7 shows the CCT product with nano-crystal, $\sim 5 \mathrm{~nm}$ size, and associated selected area electron diffraction pattern (inset) containing very fine spotty rings and extremely diffuses diffraction contrast consistent with a nano-structured product.

Figure 8 shows the frequency dependence di-electric permittivity of $\mathrm{MgAl}_{2} \mathrm{O}_{4}$ processed in EDAMM. Review of other publications [19], di-electric constant of $\mathrm{MgAl}_{2} \mathrm{O}_{4}$ processed in other synthesised method presents di-electric constant 7.8. But in our synthesised method we got 78 . But this work $\mathrm{MgAl}_{2} \mathrm{O}_{4}$ processed in EDAMM method goes up to 78 indicating EDAMM gives much better performance of di-electric properties than other conventional ball milling method. EDAMM can produce nanostructural product, which is responsible for di-electric properties.

Figure $5 \mathrm{XRD}$ pattern of $\mathrm{MgAl}_{2} \mathrm{O}_{4}$ prepared from EDAMM (see online version for colours)

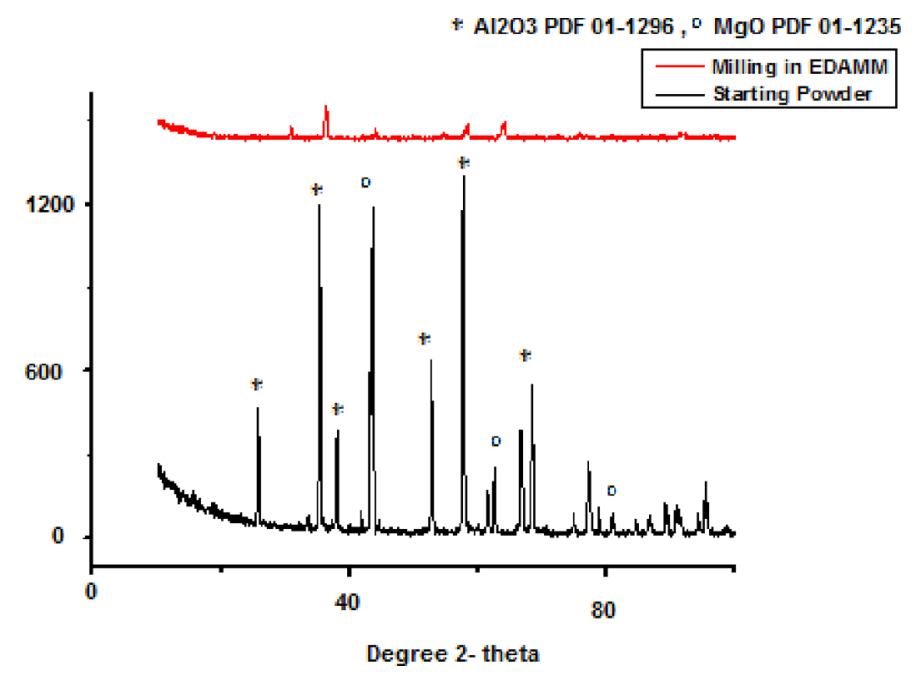

Figure 6 XRD pattern of CCT prepared by EDAMM processing of oxide starting powders (see online version for colours)

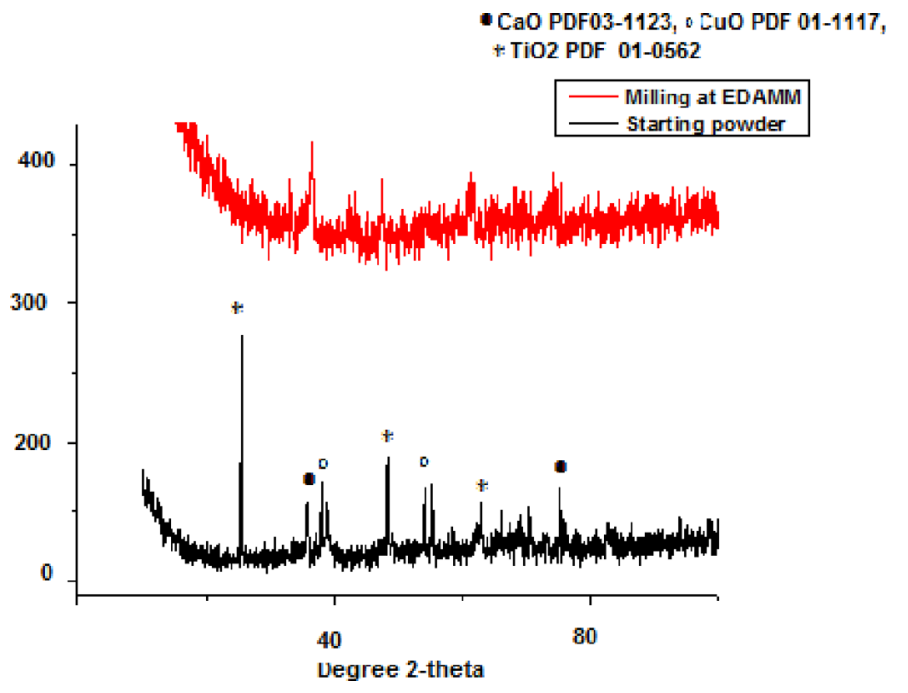


The measured di-electric constants of the samples prepared by EDAMM processing were found to decrease drastically at low frequencies and with increasing frequencies di-electric constant shows constant value. Figure 9 reveals same phenomena for CCT. At high frequency, di-electric constant gives a constant value.

Figure 7 TEM of CCT at EDAMM processed revealed fine nanocrystals, $\sim 5 \mathrm{~nm}$ size. The inset SAED pattern displays very fine spotty rings additional extremely diffuse diffraction contrast (see online version for colours)

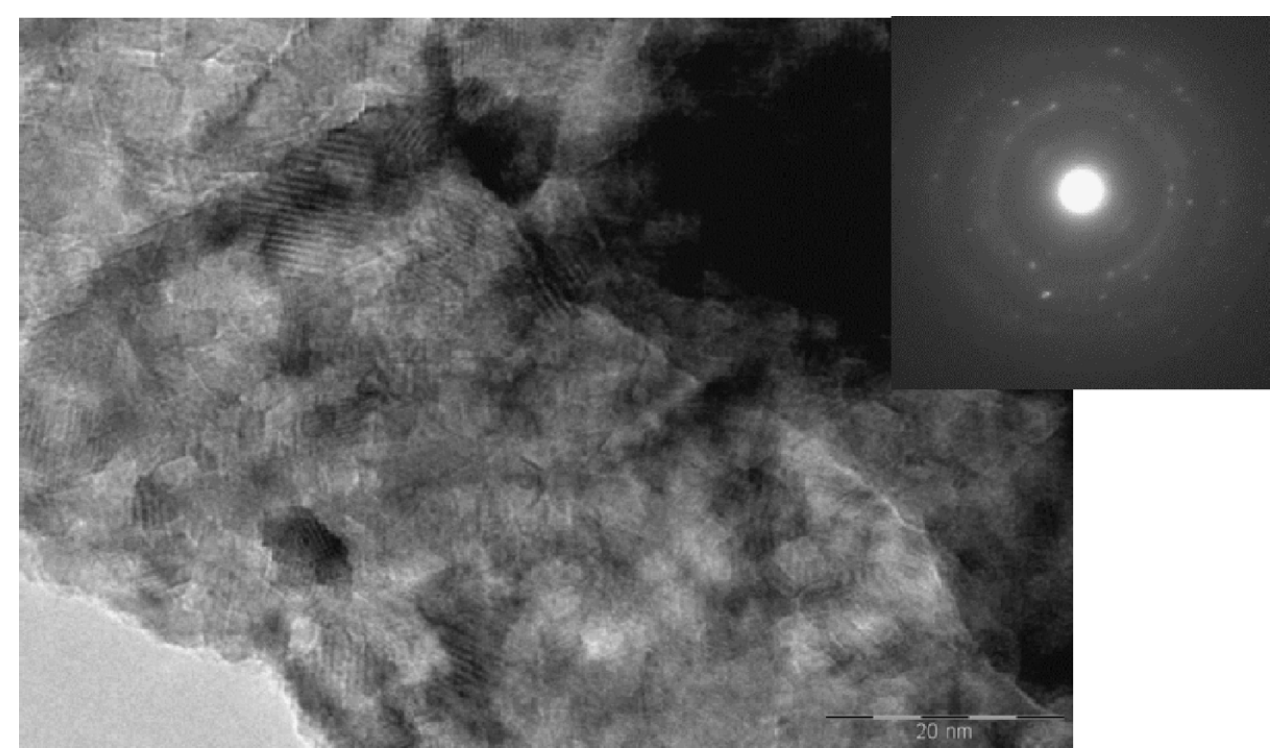

Figure 8 Frequency dependence di-electric permittivity of $\mathrm{MgAl}_{2} \mathrm{O}_{4}$ processed in EDAMM (see online version for colours)

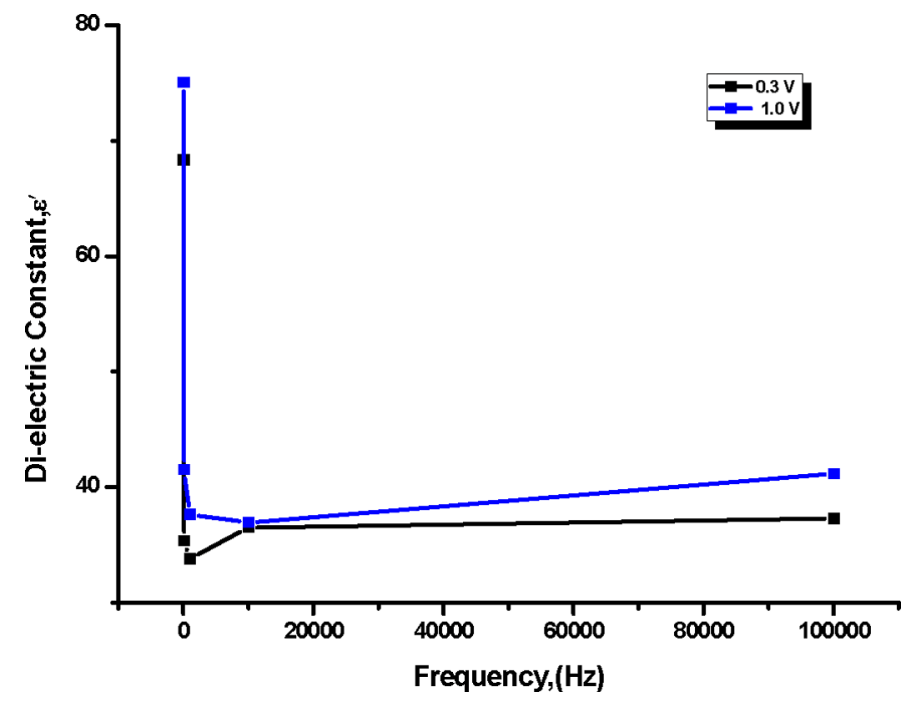


Figure 9 Frequency dependence di-electric permittivity of CCT processed in EDAMM (see online version for colours)

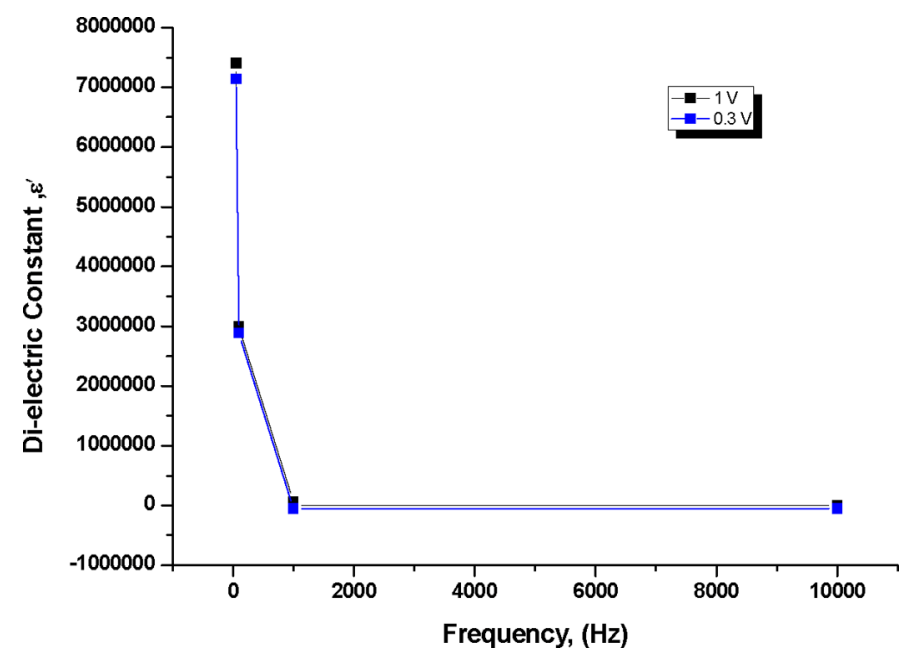

\section{Conclusions}

On the basis of these results, one can conclude that both magneto-ball milling and electric discharge assisted mechanical milling lead to the formation of nano-structural precursor powders which transform on heating into high di-electric CCT and $\mathrm{MgAl}_{2} \mathrm{O}_{4}$ supercapacitors. A high value of di-electric constant was measured, and the frequency dependence of the di-electric constant has been observed. Using these two methods, we believe that other spinel or perovskite structure oxides can be synthesised and processed for various applications in the electronics industry.

\section{Acknowledgement}

This investigation was supported by funding from the Australian Research Council Discovery Grant No. DP1093952. UOW Electron Microscopy Centre equipment was funded by ARC grants LE 0882813 and LE0237478.

\section{References}

1 Arico, A.S., Bruce, P., Scrosati, B., Tarascon, J.M. and Van Schalkwijk, W. (2005) 'Nanostructured materials for advanced energy conversion and storage devices', Nature Mater., Vol. 4, pp.366-377.

2 Futaba, D.N., Hata, K., Yamada, T., Hiraoka, T., Hayamizu, Y., Kakudate, Y., Tanaike, O., Hatori, H., Yumura, M. and Iijima, S. (2006) 'Shape-engineerable and highly densely packed single-walled carbon nanotubes and their application as super-capacitor electrodes', Nature Mater., Vol. 12, pp.987-994.

3 Kaempgen, M., Chan, C.K., Ma, J., Cui, Y. and Gruner, G. (2009) 'Printable thin film supercapacitors using single-walled carbon nanotubes', Nano Lett., Vol. 9, No. 5, pp.1872-1876. 
4 Reddy, A.L.M., Shaijumon, M.M., Gowda, S.R. and Ajayan, P.M. (2009) 'Coaxial $\mathrm{MnO}_{2}$ /carbon nanotube array electrodes for high performance lithium batteries', Nano Lett., Vol. 9, No. 3, pp.1002-1006.

5 Burke, A. (2000) 'Ultracapacitors: why, how, and where is the technology', J. Power Sources, Vol. 91, No. 1, pp.37-50.

6 Goldstein, A., Goldenberg, A., Yeshurun, Y. and Hefetz, M. (2008) 'Transparent $\mathrm{MgAl}_{2} \mathrm{O}_{4}$ spinel from a powder prepared by flame spray pyrolysis', J. Am. Ceram. Soc., Vol. 91, No. 12, pp.4141-4144.

7 Pei, L.Z., Yin, Y., Wang, J.F., Chen, J. and Zhang, Q.F. (2010) 'Low temperature synthesis of magnesium oxide and spinel powders by sol-gel process, Mater. Res. Ibero Am. J. Mater., Vol. 13, pp.339-343.

8 Kaluza, S. (2009) 'On the role of aging, washing, and drying in the synthesis of polycrystalline zinc oxide by precipitation: combining fast continuous mixing, spray drying and freeze drying to unravel the solid-state transformations of the precipitate', Catal. Lett., Vol. 129, Nos. 3-4, pp.287-292.

9 Ali, N.J. and Milne, S.J. (2006) 'Comparison of powder synthesis routes for fabricating $\left(\mathrm{Ba}_{0.65} \mathrm{Sr}_{0.35}\right) \mathrm{TiO}_{3}$ ceramics', J. Mater. Res., Vol. 21, No. 6, pp.1390-1398.

10 Goldstein, A., Goldenberg, A. and Hefetz, M. (2009) 'Transparent polycrystalline $\mathrm{MgAl}_{2} \mathrm{O}_{4}$ spinel with submicron grains, by low temperature sintering', J. Ceram. Soc. Jpn., Vol. 117, No. 1371, pp.1281-1283.

11 Goldstein, A., Goldenberg, A., Yeshurun, Y. and Hefetz, M. (2008) 'Transparent $\mathrm{MgAl}_{2} \mathrm{O}_{4}$ spinel from a powder prepared by flame spray pyrolysis', J. Am. Ceram. Soc., Vol. 91, No. 12, pp.4141-4144.

12 Pei, L.Z., Yin, Y., Wang, J.F., Chen, J. and Zhang, Q.F. (2010) 'Low temperature synthesis of magnesium oxide and spinel powders by sol-gel process, Mater. Res. Ibero Am. J. Mater., Vol. 13, pp.339-343.

13 Khalil, N.M., Hassan, M.B., Ewais, E.M.M. and Saleh, F.A. (2010) 'Sintering, mechanical and refractory properties of MA spinel prepared via co-precipitation and sol-gel techniques', J. Alloys Compd., Vol. 496, Nos. 1-2, pp.600-607.

14 Montouillout, V., Massiot, D., Douy, A. and Coutures, J.P. (1999) 'Characterization of $\mathrm{MgAl}_{2} \mathrm{O}_{4}$ precursor powders prepared by aqueous route', J. Am. Chem., Vol. 82, No. 12, pp.3299-3304.

15 Dhak, D. and Pramanik, P. (2006) 'Particle size comparison of soft-chemically prepared transition metal (Co, Ni, Cu, Zn) aluminate spinels', J. Am. Chem., Vol. 89, No. 3, pp.1014-1021.

16 Pati, R.K. and Pramanik, P. (2000) 'Low-temperature chemical synthesis of nanocrystalline $\mathrm{MgAl}_{2} \mathrm{O}_{4}$ spinel powder', J. Am. Chem., Vol. 83, No. 7, pp.1822-1824.

17 Gleitrr, H. (1989) 'Nanocrystalline materials', Prog. Mater. Sci., Vol. 33, p.223.

18 Calka, A. and Radlinski, A.P. (1991) 'Universal high performance ball-milling device and its application for mechanical alloying’, Mater. Sci. Eng., A, Vol. 134, pp.1350-1353.

19 Schreyeck, L., Wlosik, A. and Fuzellier, H. (2001) 'Influence of the synthesis route on $\mathrm{MgAl}_{2} \mathrm{O}_{4}$ spinel properties', J. Mater. Chem., Vol. 11, pp.483-486. 